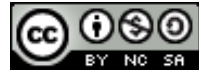

https://doi.org/10.31743/abmk.13305

\title{
FOTOGRAFIE PRZECHOWYWANE W ARCHIWUM PROWINCJI OO. BERNARDYNÓW W KRAKOWIE I ARCHIWUM KLASZTORU OO. BERNARDYNÓW W KALWARII ZEBRZYDOWSKIEJ DOKUMENTUJĄCE HISTORIE CANKTUARIUM PASYJNO-MARYJNEGO W KALWARII ZEBRZYDOWSKIEJ
}

\begin{abstract}
Streszczenie
Archiwum Prowincji oo. Bernardynów w Krakowie i Archiwum Klasztoru oo. Bernardynów w Kalwarii Zebrzydowskiej posiadają największy zasób fotografii dokumentujących historię sanktuarium pasyjno-maryjnego w Kalwarii Zebrzydowskiej. W 1999 r. obiekt ten został wpisany na listę światowego dziedzictwa UNESCO, a w 2000 r. uznano go za Pomnik Historii Polski. W niniejszym artykule zaprezentowano jego spuściznę fotograficzną. Kolekcje tych zbiorów w większości wymagają opracowania, zdigitalizowania i czekają na udostępnienie w formie wirtualnej. Wiele zdjęć należy jeszcze uporządkować. Znajdują się one w rozproszeniu przede wszystkim w Archiwum Prowincji przy aktach personalnych poszczególnych zakonników. Miejmy nadzieję, że w niedługim czasie znajdą swoje miejsce w powstałym w 2008 r. Narodowym Archiwum Cyfrowym, które w swoich zbiorach posiada największy zasób fotografii.
\end{abstract}

Słowa kluczowe: Kalwaria Zebrzydowska; sanktuarium; klasztor; fotografie; franciszkanie; bernardyni

$* * * * *$

Ruch pielgrzymkowy do Ziemi Świętej, ożywiony w Polsce w XVI wieku, znacznie przyczynił się do rozkwitu wśród wiernych kultu Męki Pańskiej, wprowadzając jego nowe formy - kalwarie. Historia jednej z nich, Zebrzydowskiej,

\footnotetext{
* Aleksander Krzysztof Sitnik - dr hab. nauk humansitycznych w zakresie historii Kościoła, Archiwum oo. Bernardynów w Kalwarii Zebrzydowskiej

e-mail: krzysztofsitnik3@gmail.com

https://orcid.org/0000-0001-5601-0492
} 
zwanej tak od nazwiska fundatora, sięga początku XVI wieku. Wojewoda krakowski Mikołaj Zebrzydowski do swojej śmierci w 1620 r. wzniósł siedemnaście kaplic, w tym trzynaście z dróżek Pana Jezusa, dwie z dróżek Matki Bożej i dwie spoza kompleksu dróżkowego. Opiekę nad kalwarią powierzył bernardynom. Kontynuatorami jego dzieła byli syn Jan i wnuk Michał Zebrzydowscy. Od $1641 \mathrm{r}$. charakter Kalwarii jako miejsca kultu Męki Pańskiej zaczął się zmieniać, bowiem klasztor bernardynów wszedł w posiadanie cudownego obrazu Matki Bożej Kalwaryjskiej. Kult maryjny w pewnym stopniu zdominował pasyjny. Większa liczba pielgrzymów zaczęła przybywać na uroczystości związane z Matką Bożą. Począwszy od drugiej połowy XVII wieku, odpusty na Znalezienie i Podwyższenie Krzyża Świętego zanikły. Zachował się odpust w Wielkim Tygodniu, podczas którego rzesze pątników uczestniczą w obchodach pasyjnych, z biegiem czasu ujętych w ramy misterium. Frekwencja wiernych wzrosła natomiast w czasie odpustów Matki Bożej Anielskiej (tzw. Porcjunkuli), Narodzenia i Wniebowzięcia Najświętszej Maryi Panny z ceremonią Pogrzebu i Tryumfu Maryi. Charakter pasyjny sanktuarium utrzymał się $\mathrm{w}$ dalszym ciągu, bowiem odpusty maryjne dawały okazję do odprawiania nabożeństwa pasyjnego: dróżek Pana Jezusa. W 1999 r. obiekt ten został wpisany na listę światowego dziedzictwa UNESCO, a w 2000 r. uznano go za Pomnik historii Polski ${ }^{1}$.

Archiwum Prowincji oo. Bernardynów w Krakowie i Archiwum Klasztoru oo. Bernardynów w Kalwarii Zebrzydowskiej posiadają największy zasób fotografii dokumentujących historię sanktuarium pasyjno-maryjnego w Kalwarii Zebrzydowskiej.

Niniejszy artykuł nie jest studium nad fotografią. Celem publikacji jest katalogowe zaprezentowanie zespołów albumów fotografii o tematyce kalwaryjskiej dwóch archiwów bernardyńskich: prowincji i klasztornego. Opis każdej jednostki zawiera: sygnaturę, sposób przechowywania fotografii (album z liczbą stron, klaser do negatywów z liczbą stron, teczka), rok jej powstania, rodzaj (kolorowa lub czarno-biała), imię i nazwisko autora-fotografa i opis treści fotografii (jeżeli dane są dostępne).

Na końcu publikacji zwróciłem uwagę na bardzo bogate archiwum cyfrowe fotografii klasztoru kalwaryjskiego. Zaprezentowałem program uroczystości religijno-kulturalnych w sanktuarium na 2021 r., aby uświadomić, jak wiele wydarzeń dokumentuje się fotografią w ciągu jednego tylko roku. Zasadne jest zatem zaprezentowanie spuścizny fotograficznej sanktuarium kalwaryjskiego.

${ }^{1}$ A.K. Sitnik, Koronacja obrazu Matki Bożej Kalwaryjskiej w 1887 roku, w: Kościól w Polsce. Dzieje i kultura, t. 17, red. J. Walkusz, Lublin 2018, s. 73-115; H.E. Wyczawski, Kalwaria Zebrzydowska. Historia klasztoru bernardynów i kalwaryjskich Dróżek, wyd. 2, uzup. M. Rudyk, Kalwaria Zebrzydowska 2006; Kalwaria Zebrzydowska - Polska Jerozolima skarbem Kościoła i Narodu Polskiego, red. C. Gniecki, Kalwaria Zebrzydowska 2002; W. Murawiec, Kalwaria Zebrzydowska. Informator - przewodnik po zabytkach sztuki i architektury sakralnej, Kalwaria Zebrzydowska 2001; H.E. Wyczawski, Kalwaria Zebrzydowska, w: Klasztory bernardyńskie w Polsce w jej granicach historycznych, red. H.E. Wyczawski, Kalwaria Zebrzydowska 1985, s. 113-122. 


\section{Fotografie kalwaryjskie w Archiwum Prowincji oo. Bernardynów w Krakowie}

W zasobie Archiwum Prowincji oo. Bernardynów w Krakowie zespół albumów fotografii obejmuje 64 jednostki, oznaczone sygnaturami od RGP-1-1 do RGP-1-64². W zespole tym znajduje się m.in.: osiem tomów albumów z 471 zdjęciami bernardynów z lat 1860-1957, ułożonymi przez o. Hieronima Eugeniusza Wyczawskiego; album fotografii bernardynów i osób świeckich z lat 1900-1950, ze zbiorów o. Fidelisa Kędzierskiego; album fotografii kleryków, wychowawców i przełożonych WSD oo. Bernardynów w Krakowie z lat 1948-1949, ze zbiorów o. Fidelisa Kędzierskiego; album fotografii Krucjaty Eucharystycznej prowadzonej przez bernardynów we Lwowie z lat 1938-1943, ze zbiorów o. Fidelisa Kędzierskiego; albumy fotografii klasztorów bernardyńskich w Alwernii, Brzeżanach, Dubnie, Dukli, Kalwarii Zebrzydowskiej, Krakowie, Leżajsku, Rzeszowie, Skępem, Tarnowie, Warszawie-Czerniakowie, Widawie; album 99 fotografii wykonanych przez br. Januarego Wilka podczas ogólnopolskiej pielgrzymki w $1935 \mathrm{r}$. do Ziemi Świętej, Grecji i Turcji; albumy fotografii z Harbinu w Mandżurii, Haukow, Sachalinu japońskiego, Pekinu, Kulgan, Teganfu, Szanghaju, Nagasaki, Tokio i innych miejscowości w Chinach i Japonii z lat 1911-1969, dedykowane bernardynowi, wikariuszowi apostolskiemu na południową Syberię, o. Gerardowi Piotrowskiemu; album fotografii bernardyńskich misjonarzy na Sachalinie japońskim z pierwszej połowy XX wieku; album fotografii ukazujących kult św. Jana z Dukli; album fotografii Biblioteki Katolickiego Uniwersytetu Lubelskiego ze zbiorów jej dyrektora o. Romualda Gustawa.

W Archiwum Prowincji oo. Bernardynów w Krakowie w zespole albumów fotografii znajduje się 16 jednostek dokumentujących historię sanktuarium pasyjno-maryjnego w Kalwarii Zebrzydowskiej:

1. Album fotografii klasztoru bernardynów w Kalwarii Zebrzydowskiej opatrzony sygnaturą RGP-1-14. Dokumentuje budowle klasztorne, kościelne i kaplice dróżkowe z 1960 r. ${ }^{3}$ Album o szerokości $352 \mathrm{~mm}$ i wysokości $254 \mathrm{~mm}$, oprawiony w płótno, zawiera 40 fotografii wykonanych w Kalwarii Zebrzydowskiej. Obejmuje 20 kart.

2. Album fotografii oznaczony sygnaturą RGP-1-15. Dokumentuje misteria w Wielkim Tygodniu w Kalwarii Zebrzydowskiej w 1960 r. Album o szerokości $352 \mathrm{~mm}$ i wysokości $254 \mathrm{~mm}$, oprawiony w płótno, zawiera 22 kolorowe fotografie wykonane przez Marka Stobińskiego w Kalwarii Zebrzydowskiej. Obejmuje 20 kart.

3. Album fotografii czarno-białych opatrzony sygnaturą RGP-1-28. Dokumentuje budowle klasztorne i obiekty na Dróżkach Pana Jezusa w Kalwarii Zebrzydowskiej z lat 30. XX wieku. Album o szerokości $330 \mathrm{~mm}$ i wysokości $240 \mathrm{~mm}$, oprawiony w płótno, zawiera 92 zdjęcia. Obejmuje 29 kart.

${ }^{2}$ Zob. H. E. Wyczawski, Katalog Archiwum Prowincji OO. Bernardynów w Krakowie, Lublin 1961 (nadbitka z „Archiwa, Biblioteki i Muzea Kościelne”, t. 3-6: 1961-1963).

${ }^{3}$ Zob. o renowacji budowli: H.E. Wyczawski, Kalwaria Zebrzydowska. Historia klasztoru bernardynów i kalwaryjskich Dróżek, s. 192. 
4. Album fotografii czarno-białych opatrzony sygnaturą RGP-1-29. Dokumentuje zabudowania klasztorno-kościelne w Kalwarii Zebrzydowskiej w XX wieku. Album o szerokości $330 \mathrm{~mm}$ i wysokości $240 \mathrm{~mm}$, oprawiony w płótno, zawiera 22 zdjęcia. Obejmuje 21 kart.

5. Album fotografii czarno-białych opatrzony sygnaturą RGP-1-30. Dokumentuje uroczystości Wielkiego Tygodnia (Misterium Męki Pańskiej') w Kalwarii Zebrzydowskiej w latach 50. XX wieku. Album o szerokości $330 \mathrm{~mm}$ i wysokości $240 \mathrm{~mm}$, oprawiony w płótno, zawiera 112 zdjęć. Obejmuje 21 kart.

6. Album fotografii czarno-białych opatrzony sygnaturą RGP-1-31. Dokumentuje sanktuarium kalwaryjskie w XX wieku. Album o szerokości $200 \mathrm{~mm}$ i wysokości $375 \mathrm{~mm}$, oprawiony w płótno. Obejmuje 91 kart.

7. Album fotografii czarno-białych opatrzony sygnaturą RGP-1-38. Dokumentuje budowle klasztoru i kościoła w Kalwarii Zebrzydowskiej w XX wieku. Album o szerokości $250 \mathrm{~mm}$ i wysokości $185 \mathrm{~mm}$, oprawiony w płótno, zawiera 24 zdjęcia na stronach 37-65. Pochodzi ze zbiorów bernardyna o. Fidelisa Kędzierskiego.

8. Album fotografii czarno-białych oznaczony sygnatura RGP-1-48. Dokumentuje m.in. budowle klasztoru bernardynów w Kalwarii Zebrzydowskiej około 1960 r. Album o szerokości $340 \mathrm{~mm}$ i wysokości $240 \mathrm{~mm}$, oprawiony w płótno, zawiera 48 zdjęć. Powstał z inicjatywy bernardyna o. H.E. Wyczawskiego.

9. Album fotografii czarno-białych opatrzony sygnaturą RGP-1-49. Dokumentuje Wielki Tydzień oraz odpust Wniebowzięcia Najświętszej Maryi Panny w Kalwarii Zebrzydowskiej w 1956 r. ${ }^{5}$ Album o szerokości 340 mm i wysokości $240 \mathrm{~mm}$, oprawiony w półpłótno, zawiera 86 zdjęć. Został wykonany przez bernardyna o. Daniela Ziółkowskiego. Obejmuje 40 stron.

10. Album fotografii kolorowych opatrzony sygnaturą RGP-1-56. Dokumentuje pobyt św. Jana Pawła II w Krakowie w 1987 r. ${ }^{6}$ Album o szerokości 340 mm i wysokości $240 \mathrm{~mm}$, oprawiony w ceratę, zawiera 47 zdjęć. Obejmuje 50 stron.

11. Album fotografii czarno-białych opatrzony sygnaturą RGP-1-57. Dokumentuje życie Służby Liturgicznej Ołtarza prowadzonej przez o. Stanisława Szydełkę w Kalwarii Zebrzydowskiej w XX wieku. Album o szerokości 360 mm i wysokości $260 \mathrm{~mm}$, oprawiony w ceratę, zawiera 21 zdjęć. Obejmuje 31 stron.

${ }^{4}$ Autorem tekstów i reżyserem misterium pasyjnego był od 1947 r. bernardyn o. Augustyn Chadam. Melodię i harmonizację tekstów śpiewanych opracował bernardyn o. Wiktoryn Swajda; tamże, s. 369-372.

${ }^{5}$ Zob. A.K. Sitnik, Bernardyńskie sanktuarium pasyjno-maryjne w Kalwarii Zebrzydowskiej w czasach komunistycznej dyktatury (1947-1979) w świetle akt IPN, „Studia Franciszkańskie”, 20 (2010) s. 351-394; tenże, Uroczystości Wniebowzięcia Matki Bożej w Kalwarii Zebrzydowskiej 1959-1961 w świetle wybranych akt IPN, „Przegląd Kalwaryjski”, 10 (2006) s. 507-515.

${ }^{6} 10$ czerwca 1987 r. podczas trzeciej pielgrzymki do Polski św. Jan Paweł II przewodniczył uroczystości stulecia koronacji wizerunku Matki Bożej Kalwaryjskiej w Krakowie na Błoniach, składając jako wotum złotą różę; H.E. Wyczawski, Kalwaria Zebrzydowska. Historia klasztoru bernardynów i kalwaryjskich Dróżek, s. 347. 
12. Album fotografii kolorowych opatrzony sygnaturą RGP-1-58. Dokumentuje życie Niższego Seminarium Duchownego w Kalwarii Zebrzydowskiej ${ }^{7}$ w XX wieku. Album o szerokości $360 \mathrm{~mm}$ i wysokości $260 \mathrm{~mm}$, oprawiony w ceratę, zawiera 71 zdjęć. Obejmuje 21 kart.

13. Klaser do negatywów fotoselekt opatrzony sygnaturą RGP-1-59. Zawiera mikrofilmy o tematyce m.in. kalwaryjskiej z lat 1987-1991. Są to: Misteria Pasyjne w czasie Wielkiego Tygodnia w Kalwarii Zebrzydowskiej w 1987 r.; wizyta sekretarza stanu Stolicy Apostolskiej, kardynała Agostino Casaroli (†1998) w Kalwarii Zebrzydowskiej w sierpniu 1987 r.; pogrzeb brata zakonnego Kazimierza Plichty w 1990 r. ; wizyta generała zakonu Braci Mniejszych o. Johna Vaughna w Kalwarii Zebrzydowskiej w 1987 r. ${ }^{9}$; Błonia w Krakowie, 10 czerwca 1987 r. ${ }^{10}$; zjazd młodzieży w Kalwarii Zebrzydowskiej 15 maja $1987 \mathrm{r}^{11}$; budowa gmachu Wyższego Seminarium Duchownego w Kalwarii Zebrzydowskiej ${ }^{12}$; przebudowa Placu Rajskiego przed bazyliką w listopadzie 1991 r. Fotoselekt obejmuje 55 kart.

14. Klaser do negatywów fotoselekt opatrzony sygnaturą RGP-1-60. Zawiera mikrofilmy m.in. o tematyce kalwaryjskiej z lat 1987-1991. Są to: obchody jubileuszu 100. rocznicy koronacji cudownego obrazu Matki Bożej Kalwaryjskiej w sierpniu 1987 r. ${ }^{13}$; wieczór powołaniowy w sierpniu 1990 r.; obchody Wielkiego Tygodnia w latach 1990-1991; XXIII sympozjum misyjne dla kleryków w Kalwarii Zebrzydowskiej, po raz pierwszy odbyte w 1988 r.; jasełka braci kleryków bernardyńskich I i II kursu w 1990 r.; poświęcenie kamienia węgielnego pod budowę WSD oo. Bernardynów w Kalwarii Zebrzydowskiej przez generała zakonu o. Johna Vaughna 3 maja 1987 r. ${ }^{14}$; obchody 350-lecia obecności obrazu Mat-

${ }^{7}$ Niższe Seminarium Duchowne funkcjonowało przy klasztorze bernardynów w Kalwarii Zebrzydowskiej w latach 1957-1989; tamże, s. 283-284.

${ }^{8}$ W 1990 r. na pogrzeb brata zakonnego Kazimierza Plichty przybył bp Kazimierz Górny; zob. tamże, s. 259, 330, 346-347, 429.

${ }^{9}$ O. John Vaughn był generałem zakonu braci mniejszych w latach 1979-1991. Zmarł w 2016 r.; zob. tamże, s. 453.

1010 czerwca 1987 r. odbyło się spotkanie papieża Jana Pawła II z Matką Bożą Kalwaryjską w Jej cudownym obrazie, który specjalnie przywieziono z sanktuarium kalwaryjskiego na Błonia w Krakowie; tamże, s. 168.

${ }^{11}$ Zob. tamże, s. 168.

${ }^{12}$ Budowa gmachu WSD oo. Bernardynów w Kalwarii Zebrzydowskiej trwała od 1984 do 1993 r.; A.K. Sitnik, Od Lwowa do Kalwarii Zebrzydowskiej. Dzieje bernardyńskiego studium filozoficzno -teologicznego, w: Kościót w Polsce. Dzieje i kultura, t. 11, red. J. Walkusz, Lublin 2012, s. 161-176; A. Chadam, Wyższe Seminarium Duchowne oo. Bernardynów (1931-1994), „Przegląd Kalwaryjski", 1 (1995) s. 29-31.

${ }^{13}$ W 1987 r. obchodzono w Kalwarii Zebrzydowskiej pod patronatem metropolity krakowskiego, kardynała Franciszka Macharskiego, jubileusz stulecia koronacji obrazu Matki Bożej Kalwaryjskiej, poprzedzony trwającą dziewięć lat nowenną, rozpoczętą przez św. Jana Pawła II w tymże sanktuarium 7 czerwca 1979 r.; H.E. Wyczawski, Kalwaria Zebrzydowska. Historia klasztoru bernardynów i kalwaryjskich Dróżek, s. 168.

${ }^{14}$ Tamże, s. 453. 
ki Bożej Kalwaryjskiej w Kalwarii Zebrzydowskiej w maju 1991 r. ${ }^{15}$ Fotoselekt obejmuje 14 kart.

15. Klaser do negatywów fotoselekt opatrzony sygnaturą RGP-1-61. Zawiera mikrofilmy o tematyce m.in. kalwaryjskiej z lat 1987-1990. Są to: święcenia prezbiteratu przez biskupa krakowskiego Juliana Groblickiego 4 czerwca 1987 r. ${ }^{16}$; odpust Wniebowzięcia NMP w sierpniu 1990 r.; obchody jubileuszu 100. rocznicy koronacji cudownego obrazu Matki Bożej Kalwaryjskiej w sierpniu 1987 r. Fotoselekt obejmuje 28 kart.

16. Klaser do negatywów fotoselekt opatrzony sygnaturą RGP-1-62. Zawiera mikrofilmy o tematyce m.in. kalwaryjskiej z lat 1987-1991. Są to: budowa gmachu WSD oo. Bernardynów w Kalwarii Zebrzydowskiej; uroczystości Wielkiego Tygodnia w latach 1987-1988; obraz Matki Bożej Kalwaryjskiej przed konserwacją. Fotoselekt obejmuje 28 kart.

\section{Fotografie kalwaryjskie w Archiwum Klasztoru oo. Bernardynów w Kal- warii Zebrzydowskiej}

W Archiwum Klasztoru oo. Bernardynów w Kalwarii Zebrzydowskiej w zespole albumów fotografii znajduje się 12 jednostek dokumentujących historię sanktuarium pasyjno-maryjnego w Kalwarii Zebrzydowskiej:

1. Teczka nr 68. Fotografie: duchowieństwo, zakonnicy, biskupi. Pielgrzymi kalwaryjscy.

2. Teczka nr 69. Fotografie: kalwaryjskie różne; zdjęcia z gablot kościelnych.

3. Teczka nr 70. Fotografie: zdjęcia z gablot kościelnych, różne.

4. Teczka nr 71. Fotografie: kalwaryjskie stare, różne. Kalwaryjskie przeźrocza, negatywy różne. Negatywy obrazu Matki Bożej Kalwaryjskiej i innych obrazów.

5. Teczka nr 72. Fotografie: odpust Wniebowzięcia, różne.

6. Teczka nr 73. Fotografie: misteria Wielkiego Tygodnia z różnych lat.

7. Teczka nr 74. Fotografie: pielgrzymka bernardyńska z obrazem Matki Bożej Kalwaryjskiej do Rzymu.

8. Teczka nr 75. Fotografie: papież Benedykt XVI w Kalwarii Zebrzydowskiej, $2006 \mathrm{r}$.

9. Teczka nr 76. Fotografie: kalwaryjskie argenteria i szaty liturgiczne. Różne stare fotografie.

10. Teczka nr 77. Fotografie: bazylika, kaplice, obrazy i inne. Zniszczenia na Dróżkach po wichurze w 2007 r. Odsłonięcie tablicy UNESCO. Peregrynacja obrazu Matki Bożej Jasnogórskiej w 2003 r.

${ }^{15}$ W 1991 r. przypadła 350. rocznica objęcia w posiadanie przez bernardynów w Kalwarii Zebrzydowskiej cudownego wizerunku Matki Bożej, podarowanego im przez Stanisława Paszkowskiego. Z tej okazji odbyły się w dniach 2-5 maja $1991 \mathrm{r}$. uroczystości jubileuszowe; tamże, s. $171-172$.

${ }^{16}$ W 1987 r. w Kalwarii Zebrzydowskiej biskup krakowski Julian Groblicki wyświęcił sześciu bernardyńskich prezbiterów: oo. Huberta Frajkowskiego, Krystiana Olszewskiego, Zenobiusza Żaka, Ottona Pierzchałę, Wita Okulskiego i Wojciecha Frączyka. 
11. Teczka nr 78. Fotografie: kaplic i kościołów na Dróżkach. Album: papież Jan Paweł II w Kalwarii w 1979 r., papież Jan Paweł II na Błoniach w Krakowie dar Złotej Róży w 1987 r. Rewizyty bernardynów u Jana Pawła II w Rzymie.

12. Teczka nr 84. Fotografie: plany zdjęciowe obiektów kalwaryjskich, obrazy i epitafia, ołtarze, kaplica Matki Bożej Kalwaryjskiej, krużganki, wnętrze bazyliki i korytarze, ambona, chór zakonny, kaplica św. Antoniego, kalwaryjskie różne.

W każdej teczce znajduje się od 100 do 150 zdjęć luźnych, czarno-białych lub kolorowych.

Od 2005 r. sanktuarium kalwaryjskie ma stronę internetową: http://kalwaria. eu. W zakładce Kalwaria papieska znajdują się fotografie z pielgrzymek do Kalwarii Zebrzydowskiej papieży św. Jana Pawła II (7 czerwca 1979 r., 19 sierpnia 2002 r.) i Benedykta XVI (27 maja 2006 r.). W zakładce Multimedia można obejrzeć galerię zdjęć z ostatnich wydarzeń w kalwaryjskim sanktuarium, obraz Matki Bożej Kalwaryjskiej w 3D oraz Wirtualną Kalwarię, czyli galerię fotografii sanktuarium, dróżek Pana Jezusa, dróżek Matki Bożej i obiektów towarzyszących. W zakładce Wydarzenia znajduje się dział Aktualności, w którym można znaleźć najnowsze zdjęcia i informacje z życia sanktuarium ${ }^{17}$. Przykładowo w 2021 r. odbyły się następujące uroczystości:

- w styczniu: procesja ku czci Najświętszego Imienia Jezus; spotkanie opłatkowe przewodników kalwaryjskich, organizatorów asyst i orkiestr;

- w lutym: XVI Pielgrzymka Osób Zakonnych z okazji Dnia Życia Konsekrowanego; Dzień Chorych; rekolekcje wielkopostne;

- w marcu: nowenna i uroczystość św. Józefa Oblubieńca NMP; uroczystość Zwiastowania, Dzień Świętości Życia, mszę św. z duchową adopcją; odpust Wielkiego Tygodnia z Misterium Męki Pańskiej;

- w kwietniu: procesja rezurekcyjna z kościoła Grobu Pana Jezusa; w Domku Matki Bożej mszę św. w intencji uczestników nabożeństw pasyjnych; Msza św. w Wieczerniku; Pielgrzymka Harcerską Chorągwi Krakowskiej; początek wtorkowych nowenn przed uroczystością św. Antoniego z Padwy; odpust w kościele Grobu Pana Jezusa; procesja eucharystyczna na rozpoczęcie nabożeństw majowych;

- w maju: nabożeństwa majowe; rocznica przybycia do sanktuarium cudownego wizerunku Matki Bożej Kalwaryjskiej; odpust Znalezienia Krzyża Świętego z Mszą św. w kościele Ukrzyżowania; Dni Krzyżowe z procesją błagalną do kościoła III Upadku Pana Jezusa; rozpoczęcie nabożeństw fatimskich w kościele Grobu Matki Bożej; nowenna do Ducha Świętego; odpust Wniebowstąpienia z Mszą św. w kaplicy Wniebowstąpienia i procesją eucharystyczną; rekolekcje przewodników kalwaryjskich, organizatorów asyst i orkiestr; odpust Zesłania Ducha Świętego z Mszą św. w Wieczerniku; XV rocznica pielgrzymki Ojca św. Benedykta XVI do Kalwarii Zebrzydowskiej; XIV Piesza Pielgrzymka z Krakowa-Łagiewnik do Kalwarii Zebrzydowskiej; XVIII Ogólnopolskie Czuwanie

${ }^{17}$ A.K. Sitnik, Popularyzacja wiedzy o współczesnych klasztorach bernardynów i bernardynek w Polsce online, „Studia Franciszkańskie”, 30 (2020) s. 291. 
Modlitewne w intencji powołań; procesja eucharystyczna na zakończenie nabożeństw majowych;

- w czerwcu: procesja na rozpoczęcie nabożeństw do Najświętszego Serca Pana Jezusa; nabożeństwa czerwcowe; oktawa Bożego Ciała z nieszporami i procesją eucharystyczną; uroczystość Najświętszego Ciała i Krwi Chrystusa w „Grobku” Matki Bożej z procesją do czterech ołtarzy, Mszą św. w kościele parafialnym i procesją do bazyliki; Msza św. w Wieczerniku i procesja Bożego Ciała po Dróżkach; XLII rocznica I pielgrzymki św. Jana Pawła II do Kalwarii Zebrzydowskiej; zakończenie oktawy Bożego Ciała z Mszą św. w kościele III Upadku i procesją na wzgórzu Ukrzyżowania; uroczystość Najświętszego Serca Pana Jezusa z procesją eucharystyczną; XV Pielgrzymka Apostolatu Margaretka z drogą krzyżową; odpust św. Antoniego z Padwy z błogosławieństwem dzieci; modlitewne czuwanie fatimskie w kościele Grobu Matki Bożej; odpust ku uczczeniu narodzenia św. Jana Chrzciciela z Mszą św. w kaplicy U Heroda; procesja na zakończenie nabożeństw czerwcowych;

- w lipcu: odpust Najdroższej Krwi Pana Jezusa z Mszą św. w kaplicy U Piłata; pielgrzymka chorych z drogą krzyżową na krużgankach klasztornych; modlitewne czuwanie fatimskie w kościele Grobu Matki Bożej; odpust św. Marii Magdaleny z Mszą św. w kaplicy św. Marii Magdaleny; XL Piesza Pielgrzymka Góralska na Jasną Górę z Mszą św. w bazylice; błogosławieństwo kierowców i pojazdów;

- w sierpniu: odpust Matki Bożej Anielskiej, Patronki bazyliki; droga krzyżowa za zmarłych ze Mszą św. w kościele Ukrzyżowania; odpust Wniebowzięcia NMP; Procesja Współcierpienia NMP; uroczystość NMP Kalwaryjskiej; Procesja Zaśnięcia NMP do Domku Matki Bożej; uroczystość Wniebowzięcia NMP z Procesją Wniebowzięcia; XIX rocznica II pielgrzymki św. Jana Pawła II do Kalwarii Zebrzydowskiej; XIII Ogólnopolska Pielgrzymka Motocyklistów; XXIII Pielgrzymka Konna i Zaprzęgów Konnych przy IV stacji Wniebowzięcia; XLIX Pielgrzymka Służby Liturgicznej i Ruchu Światło-Życie; odpust ku czci męczeństwa św. Jana Chrzciciela z Mszą św. w kaplicy U Heroda;

- we wrześniu: XVI Małopolska Pielgrzymka Rzemieślników i Kupców; odpust Narodzenia NMP; Pielgrzymka Diecezji Sosnowieckiej z Dróżkami Pana Jezusa; Pielgrzymka Makowska i Olkuska; XXIX Pielgrzymka Rodzin Archidiecezji Krakowskiej z drogą krzyżową od kaplicy Piłata; modlitewne czuwanie fatimskie w kościele Grobu Matki Bożej; święto Stygmatów św. Franciszka z Asyżu z ucałowaniem relikwii; Dni Wspólnoty Młodzieży Franciszkańskiej; odpust Podwyższenia Krzyża Świętego ze Mszą św. w kościele Ukrzyżowania; nowenna do św. Franciszka z Asyżu; XIV Pielgrzymka Rodzin diecezji Bielsko-Żywieckiej z drogą krzyżową; Pielgrzymka Franciszkańskiego Zakonu Świeckich z drogą krzyżową; rozpoczęcie nabożeństw różańcowych z procesją eucharystyczną;

- w październiku: nabożeństwa różańcowe; odpust ku czci św. Franciszka z Asyżu; nieszpory i procesja różańcowa na wzgórzu Ukrzyżowania; Transitus; śluby wieczyste kleryków i braci zakonnych; IX Pielgrzymka Młodzieży Diecezji Sosnowieckiej; zakończenie nabożeństw fatimskich w kościele Grobu Matki Bożej; XXVII Pielgrzymka Duszpasterstwa Trzeźwości Archidiecezji Krakowskiej; 
Msza św. w kaplicy św. Antoniego z Padwy z racji uroczystości św. Jana Kantego, patrona archidiecezji; pielgrzymka młodzieży maturalnej z Liceum Ogólnokształcącego w Zamościu; czuwanie przed obrazem Matki Bożej Kalwaryjskiej i apel maryjny; zakończenie nabożeństw różańcowych z procesją eucharystyczną;

- w listopadzie: nabożeństwa wypominkowe za zmarłych; uroczystość Wszystkich Świętych z procesją z modlitwami za zmarłych; wspomnienie Wszystkich Wiernych Zmarłych z procesją z modlitwami za zmarłych; droga krzyżowa za zmarłych od kaplicy U Piłata; odpust ku czci św. Benedykta, Jana, Mateusza, Izaaka i Krystyna, Pierwszych Męczenników Polski, z mszą św. w kaplicy św. Marii Magdaleny; nowenna przed uroczystością Niepokalanego Poczęcia NMP;

- w grudniu: adwent - roraty; oktawa Niepokalanego Poczęcia NMP z procesją; uroczystość Niepokalanego Poczęcia NMP z procesją eucharystyczną; nowenna do Dzieciątka Jezus; nabożeństwo przebłagalno-dziękczynno-błagalne na zakończenie starego roku z nieszporami i procesją eucharystyczną ${ }^{18}$.

Każde z wyżej wymienionych wydarzeń zostało udokumentowane zdjęciami na podstronie Wydarzenia w dziale Aktualności. Cyfrowe archiwum fotografii sanktuarium pasyjno-maryjnego w Kalwarii Zebrzydowskiej znajduje się pod opieką wikarego klasztoru i zawiera kilka tysięcy zdjęć.

\section{Podsumowanie}

Kolekcje zbiorów fotograficznych sanktuarium pasyjno-maryjnego w Kalwarii Zebrzydowskiej przechowywane w Archiwum Prowincji oo. Bernardynów w Krakowie i Archiwum Klasztoru oo. Bernardynów w Kalwarii Zebrzydowskiej w większości wymagają opracowania, zdigitalizowania i czekają na udostępnienie w formie wirtualnej. Wiele zdjęć wymaga jeszcze uporządkowania. Znajdują się one w rozproszeniu przede wszystkim w Archiwum Prowincji przy aktach personalnych poszczególnych zakonników.

W zasadzie nikt jeszcze nie zwrócił uwagi na tak cenne zasoby zdjęć. Nigdy nie były one badane. Być może niniejszy artykuł stanie się inspiracją do podjęcia różnych badań nad fotografią kalwaryjską, a możliwości są szerokie: badania statystyczne, historyczne, w jaki sposób zdjęcia trafiły do prezentowanych archiwów, czy badanie treści fotografii (według wybranego aspektu) itp.

Miejmy nadzieję, że fotografie kalwaryjskie w niedługim czasie znajdą swoje miejsce w powstałym w 2008 r. Narodowym Archiwum Cyfrowym, które w swoich zbiorach posiada największy zasób fotografii.

\section{REFERENCES / BIBLIOGRAFIA}

Chadam Augustyn, Wyższe Seminarium Duchowne oo. Bernardynów (1931-1994), „Przegląd Kalwaryjski”, 1 (1995) s. 29-31.

Kalwaria Zebrzydowska - Polska Jerozolima skarbem Kościoła i Narodu Polskiego, red. C. Gniecki, Kalwaria Zebrzydowska 2002.

${ }^{18}$ Kalendarium uroczystości w roku 2021, w: Kalendarz kalwaryjski. Sanktuarium Pasyjno -Maryjne w Kalwarii Zebrzydowskiej, [Kalwaria Zebrzydowska] 2021. 
Murawiec Wiesław, Kalwaria Zebrzydowska. Informator - przewodnik po zabytkach sztuki i architektury sakralnej, Kalwaria Zebrzydowska 2001.

Sitnik Aleksander Krzysztof, Bernardyńskie sanktuarium pasyjno-maryjne w Kalwarii Zebrzydowskiej w czasach komunistycznej dyktatury (1947-1979) w świetle akt IPN, „Studia Franciszkańskie”, 20 (2010) s. 351-394.

Sitnik Aleksander Krzysztof, Koronacja obrazu Matki Bożej Kalwaryjskiej w 1887 roku, w: Kościót w Polsce. Dzieje i kultura, t. 17, red. J. Walkusz, Lublin 2018, s. 73-115.

Sitnik Aleksander Krzysztof, Od Lwowa do Kalwarii Zebrzydowskiej. Dzieje bernardyńskiego studium filozoficzno-teologicznego, w: Kościół w Polsce. Dzieje i kultura, t. 11, red. J. Walkusz, Lublin 2012, s. 161-176.

Sitnik Aleksander Krzysztof, Popularyzacja wiedzy o współczesnych klasztorach bernardynów i bernardynek w Polsce online, „Studia Franciszkańskie”, 30 (2020) s. 285 305.

Sitnik Aleksander Krzysztof, Uroczystości Wniebowzięcia Matki Bożej w Kalwarii Zebrzydowskiej 1959-1961 w świetle wybranych akt IPN, „Przegląd Kalwaryjski”, 10 (2006) s. 507-515.

Wyczawski Hieronim Eugeniusz, Kalwaria Zebrzydowska, w: Klasztory bernardyńskie $w$ Polsce w jej granicach historycznych, red. H.E. Wyczawski, Kalwaria Zebrzydowska 1985 , s. 113-122.

Wyczawski Hieronim Eugeniusz, Kalwaria Zebrzydowska. Historia klasztoru bernardynów i kalwaryjskich Dróżek, wyd. 2, uzup. M. Rudyk, Kalwaria Zebrzydowska 2006.

Wyczawski Hieronim Eugeniusz, Katalog Archiwum Prowincji OO. Bernardynów w Krakowie, Lublin 1961 (nadbitka z „Archiwa, Biblioteki i Muzea Kościelne” t. 3-6: 19611963).

\title{
PHOTOGRAPHS DOCUMENTING THE HISTORY OF PASSION- MARIAN SANCTUARY OF KALWARIA ZEBRZYDOWSKA WHICH ARE STORED IN THE PROVINCIAL ARCHIVE OF BERNARDINE FATHERS IN CRACOW \\ AND IN THE ARCHIVE OF BERNARDINE MONASTERY IN KALWARIA ZEBRZYDOWSKA
}

\begin{abstract}
The Provincial Archive of Bernardine Fathers in Cracow and the Archive of Bernardine Monastery in Kalwaria Zebrzydowska have the largest collection of photographs which document the history of passion-marian sanctuary of Kalwaria Zebrzydowska. In 1999 the complex was added to the UNESCO list of World Heritage Sites and since 2000 it has been recognized as a Polish historic monument. Hence, it is appropriate to depict the photographic legacy of the Sanctuary in the present article. Most of the collections of photographs require studies and digitalization. They are pending to be published online. Lots of photographs in the Provincial Archive and in the monastery's archive require ordering. They are scattered mostly in the Provincial Archive over the personal records of particular monks. Hopefully, soon they will find their place in the National Digital Archives, formed in 2008, which stores the biggest collection of photographs.
\end{abstract}

Keywords: Kalwaria Zebrzydowska; sanctuary; monastery; photograph; Franciscans, Bernardines 